CASE REPORT

\title{
Primary omental hydatid cyst
}

\author{
Halil Alis' \\ Selin Kapan' \\ Osman Öner' \\ Aliye Soylu ${ }^{2}$ \\ Kemal Dolay' \\ Mustafa U Kalayci' \\ Ersan Aygun' \\ 'Department of General Surgery; \\ 2Department of Gastroenterology, \\ Bakirkoy Dr Sadi Konuk Training \\ and Research Hospital, Istanbul, \\ Turkey
}

\begin{abstract}
Hydatid disease is still a frequently seen disease in endemic area like South America, Middle Asia and South Europe as well as Turkey. Although the disease occurs more frequently in liver and lungs, it can be seen in any part of the body. In this report we present a case of isolated omental hydatid disease which is a rare entity in the English literature.
\end{abstract}

Keywords: omental hydatid cyst, surgery

\section{Introduction}

Hydatid disease essentially occurring in liver and lungs can be seen in any region of the body from brain to inguinal canal. ${ }^{1}$ Extrahepatic localization frequently occurs after hepatic involvement. Isolated omental hydatid cyst is a rare entity in English literature. $^{2}$

\section{Case report}

An 11-year-old boy was admitted to the hospital with a history of trauma to his belly and abdominal pain. Physical examination revealed a $10 \times 15 \mathrm{~cm}$ mass in the midline of the abdomen. Hematological and biochemical tests were normal. Abdominal ultrasonography (US) revealed a $10 \times 15 \mathrm{~cm}$ pure cystic lesion within the mesentery (Figure 1). Abdominal computerized tomography confirmed the diagnosis of mesenteric cystic mass of $10 \times 15 \mathrm{~cm}$ being independent of other organs of the abdominal cavity (Figure 2). The family was living in an urban environment and there was no history of being in touch with animals. Preoperative diagnosis was a cystic mass of the mesenterium and this indicated a total cyst excision. Not immediately but without delay, exploratory laparotomy was made and a cystic mass of $12 \times 15 \mathrm{~cm}$ with regular boundaries in the omentum was excised (Figure 3). Exploration revealed no other pathology within the abdomen.

Hydatid cyst of the omentum was our diagnosis after a rapid pathological examination of the mass. Following an uneventful recovery and obtaining blood sample for indirect hemaglutination (IHA) test for echinococcus granulosus, the patient was discharged at the second day postoperatively. IHA was found positive at the concentration of 1/128. The family approved scanning with abdominal USG and IHA tests and the results were normal. The patient was discharged after an uneventful recovey period with treatment of albendazole $10 \mathrm{mg} / \mathrm{kg} /$ day for six months. Outpatient follow-up included hemogram, liver function tests, IHA and abdominal sonography at the 3rd, 6th months, including a repeat sonograpy at the 12 th month. All results were in normal ranges.

\section{Discussion}

Hydatid disease is an infection caused by the larval form of Echinococcus granulosus, mostly affecting liver and lungs, which rarely develops in other organs within the abdominal cavity. ${ }^{3-5}$ Cysts may remain asymptomatic for years until causing symptoms due to their space-occupying effect within organs or systemic reactions due to perforation. ${ }^{4,6}$ 


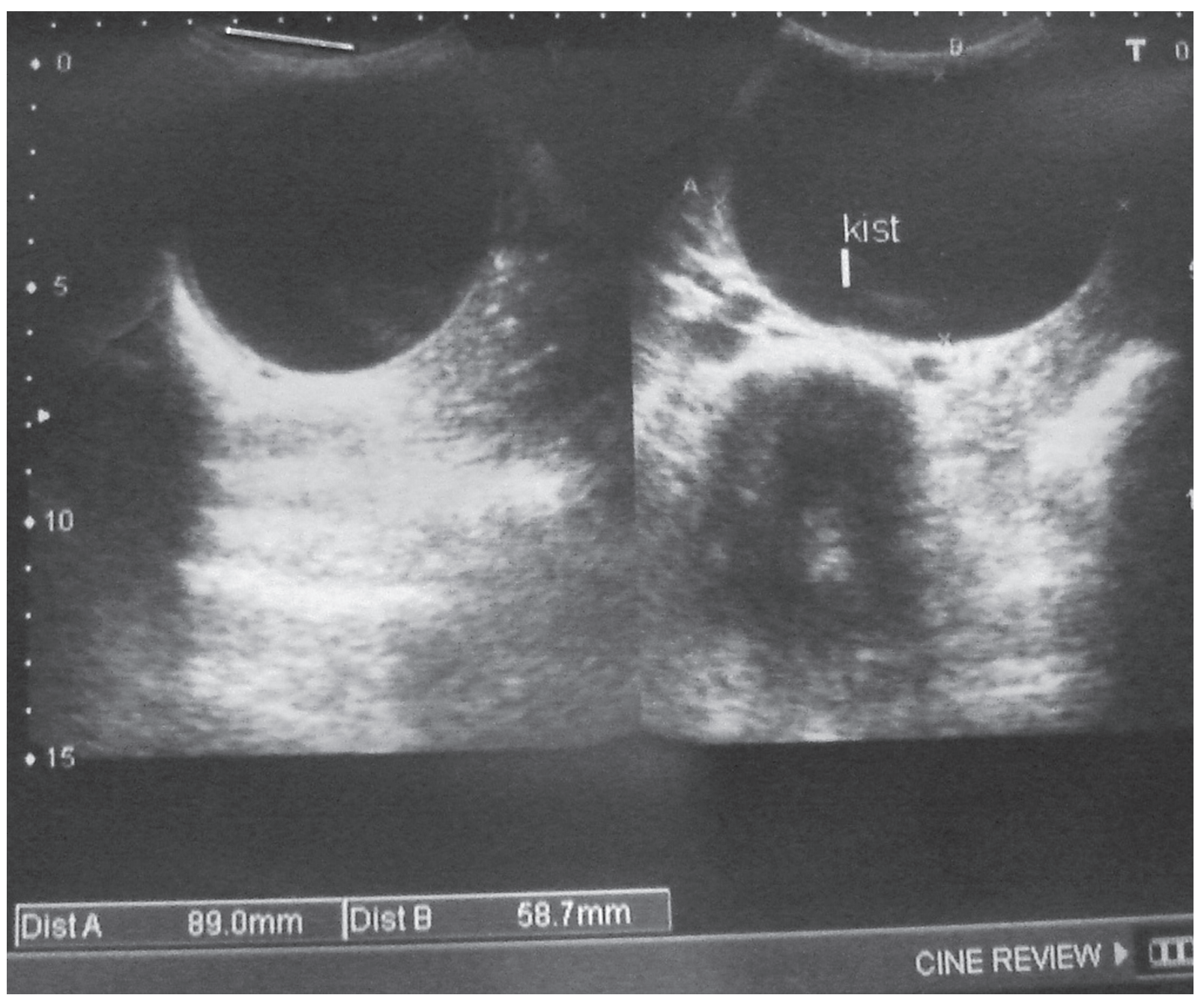

Figure I Abdominal ultrasonography image of omental cystic lesion within the mesentery.

Cysts with extrahepatic locations follow a silent course as is the case in our patient in whom diagnosis was made after clinical investigations due to a history of trauma.

For the diagnosis of cysts, the imaging modality of choice is abdominal ultrasonography. ${ }^{8}$ For mesenteric and omental cysts, abdominal CT scanning provides minimal additional information but it can reveal that the cyst is not emerging from another organ such as the kidney, pancreas, or ovary. ${ }^{9}$

Most patients have a single organ involved with a solitary cyst, but extrahepatic involvement is mostly associated with hepatic involvement. Other isolated organ involvement of E. granulosus infection are rare in the literature. Rare locations reported as sporadic cases are pancreatic, pelvic, mediastinal, heart, brain spinal cord, eye, testis, bones, urinary bladder, muscle, and skin..$^{3,6}$ There is only one case report of isolated omental hydatid cyst within the English literature. $^{2}$
The goal of the treatment of omental hydatid cyst is to treat the disease, and avoid recurrence and complications as in other forms. ${ }^{7}$ Surgery, either conservative or radical, is still the treatment of choice for multivesicule and complicated cysts of all locations although percutaneous aspiration has been gaining acceptance as an alternative to surgical therapy in uncomplicated hepatic disease. In either therapy, secondary hydatidosis as a result of spillage of cystic fluid should be avoided. Therefore pre- and postoperative albendazole therapy should be added to the treatment. ${ }^{4}$

For mesenteric cysts and hydatid cysts, laparoscopic surgery can be performed as well. ${ }^{10,11}$ In our treatment we chose open surgery because of the preoperatively unknown nature of the cyst and its relatively big dimensions for an 11-year-old child's abdominal cavity. If we could recognize the lesion as a hydatid cyst preoperatively we would prefer laparoscopic excision, but not percutaneous drainage, due to the danger of uncontrolled spillage. 

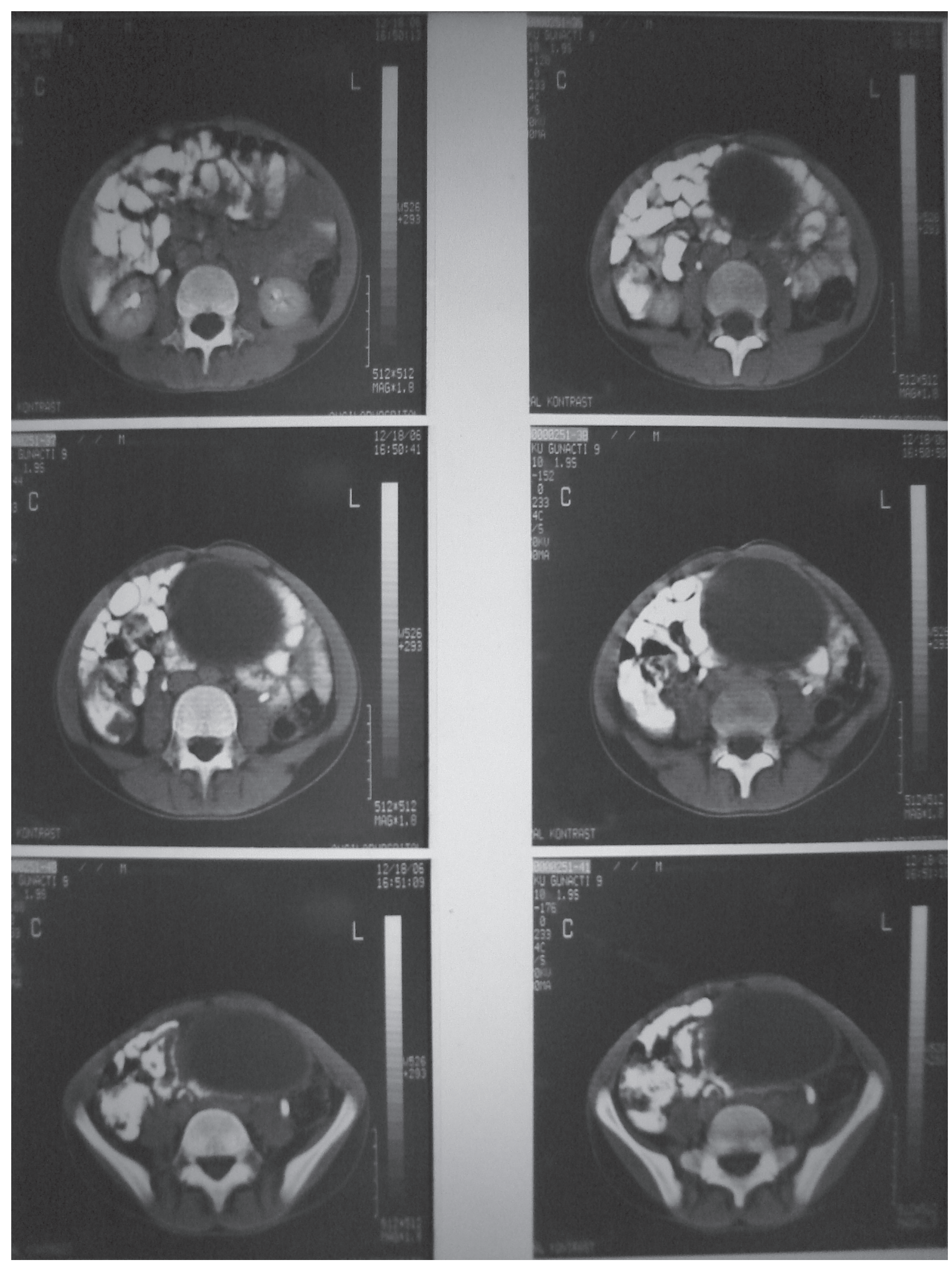

Figure 2 Abdominal computed tomography image of mesenteric cystic mass of $10 \times 15 \mathrm{~cm}$ 


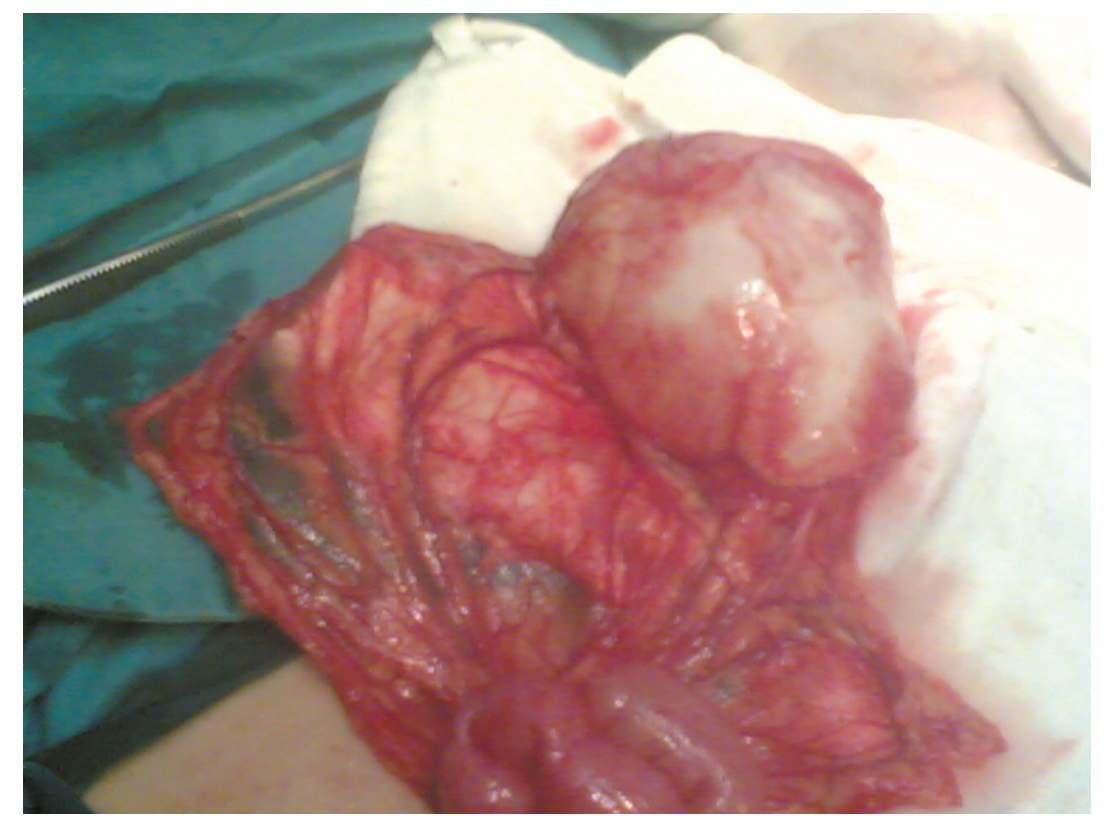

Figure 3 Cystic mass during laparotomy

Primary omental hydatid cyst should be kept in mind in the differential diagnosis of omental cysts found incidentally in endemic regions for $E$. granulosus infection. Total excision of the cyst without spillage in the abdominal cavity accompanied by albendazole therapy is the choice of treatment to avoid recurrences.

\section{Disclosure}

The authors report no conflicts of interest in this work.

\section{References}

1. Kıresi DA, Karabacakoglu A, Odev K, Karakose S. Uncommon locations of hydatid cysts. Acta Radiologica. 2003;44:622-236.

2. Sethi SK, Patnaik S, Narayan, Navak SN. Isolated omental hydatid cyst - a case report. J Indian Med Assoc. 2004;102:644-246.

3. Kutukcu E, Kapan S, Turhan AN, Ede B, Aygun E. Pankreatik kist hidatik: Olgu Sunumu. Bakirkoy Tip Dergisi. 2005;1:74-26.
4. Tsaroucha AK, Polychronidis AC, Lyrantzopoulos N, et al. Hydatid disease of the abdomen and other locations. World J Surg. 2005;29:1161-2165.

5. Gollackner B, Lange F, Auer H, et al. Radical surgical therapy of abdominal cystic hydatid disease: Factors of recurrence. World J Surg. 2000;24:717-221

6. Kern P. Echinococcus granulosus infection: clinical presentation, medical treatment and outcome. Langenbecks Arch Surg. 2003;388:413-220.

7. Kapan M, Kapan S, Goksoy E, Perek S, Kol E. Postoperative recurrence in hepatic hydatid disease. J Gastrointest Surg. 2006;10:734-239.

8. Mollitt DL, Ballantine TV, Grosfeld JL. Mesenteric cysts in infancy and childhood. Surg Gynecol Obstet. 1978;147:182-284.

9. Vanek VW, Phillips AK. Retroperitoneal, mesenteric, and omental cysts. Arch Surg. 1984;119:838-242.

10. Asoglu O, Igci A, Karanlik H, et al. Laparoscopic treatment of mesenteric cysts. Surg Endosc. 2003;17:832.

11. Maazoun K, Mekki M, Chioukh FZ, et al. Laparoscopic treatment of hydatid cyst of the liver in children. A report on 34 cases. $J$ Pediatr Surg. 2007;42:1683-2686. 